\title{
Photograph
}

\section{We're All on This Spaceship Earth}

Nancy Si, MD ${ }^{1}$

\section{Abstract}

\section{Description}

The photo features the geodesic sphere at Epcot, Disney World in Orlando, FL. Inside the dome, there was an iconic ride called "Spaceship Earth", which has since been shut down for refurbishment. This photo was taken November 2019, approximately 6 months before it was shut down. Much like how the ride emphasized the progress that human civilization has made in the last several hundred years and hopes to make in years to come, the current pandemic has shown us how far we have come in the medicine and other STEM fields. We hope only to do better and be better for everyone on our little Spaceship Earth.

\section{Keywords}

Spaceship Earth; Epcot Center; geodesic sphere; photography; art; humanities; medicine in the arts

\section{Conflicts of Interest}

The author declares she has no conflicts of interest.

The author is an employee of North Florida Regional Medical Center, a hospital affiliated with the journal's publisher.

This research was supported (in whole or in part) by HCA Healthcare and/or an HCA Healthcare affiliated entity. The views expressed in this publication represent those of the author(s) and do not necessarily represent the official views of HCA Healthcare or any of its affiliated entities.

\section{Author Affiliation}

1. University of Central Florida School of Medicine/HCA Healthcare Consortium, North Florida Regional Medical Center, Gainesville, FL

Author affiliations are listed at the end of this article.

Correspondence to: Nancy Si, MD

UCF/HCA Healthcare

Consortium

North Florida Regional

Medical Center

6500 Newberry Rd

Gainesville, FL 32605

(Nancy.Si@hcahealthcare.

com) 
HCA Healthcare Journal of Medicine

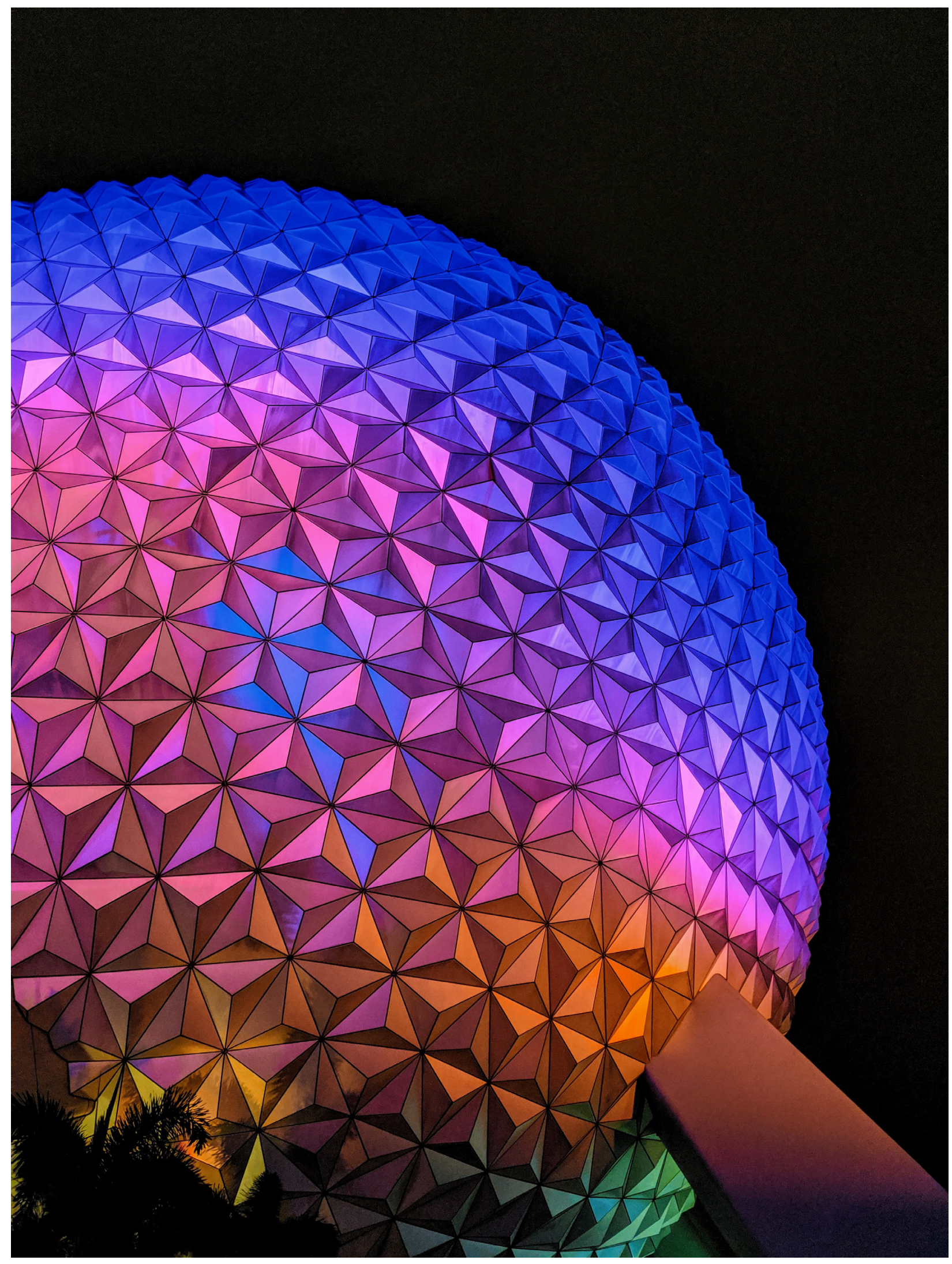

